\title{
Oral Hygiene Habits and Dental Treatment Needs of Children with Dental Fluorosis and Those Without Dental Fluorosis Aged 12-15 Years In in a High Fluoride Area in North Kajiado Kenya
}

\author{
Mildred ndoti Mavindu ${ }^{1}$, Gladys N Opinya ${ }^{2 *}$, Richard Owino and Edith Ngatia ${ }^{1}$ \\ ${ }^{1}$ Dentistry \& Orthodontics, School of Dental Sciences, University of Nairobi, Kenya \\ ${ }^{2}$ Department of Paediatric Dentistry \& Orthodontics, School of Dental Sciences, University of Nairobi, Kenya
}

Received: 畊April 13, 2018; Published: 阱 May 07, 2018

*Corresponding author: Gladys Nabubwaya Opinya, Department of Paediatric Dentistry \& Orthodontics, School of Dental Sciences, College of Health Sciences, University of Nairobi, Kenya

\section{Abstract}

Background: The dental disease identified as dental caries, periodontal, gingival lesions and dental fluorosis when diagnosed early and the treatment needs assessment with patients' perception ensures the proper use of the physical facilitates, It also enhances planning for rational health resource allocation, utilization and personnel distribution so as to tackle the health problems in a holistic way.

Objective: The objective of the study was to determine the dental treatment needs among children aged 13-17 years affected by dental fluorosis and those not affected by dental fluorosis in Kajiado North District of Kenya

Materials and Methods: Study design this was a cross sectional comparative study of the dental treatment needs among two age matched population groups in primary school children. Sampling and Sample size. Stratified random sampling was used to select four primary schools out of the primary schools in North Kajiado. All children in the school with a full permanent dentin and whose parents had signed the consent form were recruited into the study. The study involved 248 children, 98(40\%) males and $150(60 \%)$ females aged between $13-17$ years (mean age $=14.75 \pm 1.45$ ) selected by simple random sampling from 9 schools in Kajiado North District which was purposively selected. They were all clinically examined under natural light for plaque and gingival scores using the Silness and Loe 1, Loe and Silness, dental caries was recrded using the decayed Missing Filedl teeth (DMFT), while gingivitis, periodontal disease and fluorosis using indices:- Silness and Loe 1, Loe and Silness, DMFT,CPITN and TFI.

Results: The treatment needs for gingivitis were similar, majority 218 (88\%) children with fluorosis and 213 (86\%) without required oral hygiene instructions and prophylaxis. There were $3(1.2 \%)$ children who had periodontitis in the group with dental fluorosis and required scaling and root planning. There were $50 \%$ children with caries in the fluorosis group who required one surface and $24.2 \%$ for two surface amalgam/composite restorations and for those without fluorosis, $76 \%$ required one surface and $15.2 \%$ two surface amalgam/composite restorations. There were $321(60.8 \%)$ teeth surfaces which required bleaching and microabrasion or composite masking and another 207(39.2\%) for direct composite / porcelain veneers or crowns.

Conclusion: Children with dental fluorosis were burdened more by dental disease and had more treatment needs (dental caries, fluorosis, periodontal disease and gingivitis) when compared to those without dental fluorosis.

\section{Introduction}

Dental conditions like fluorosis, caries, gingival and periodontal diseases require varied treatment approaches to manage them depending on the severity hence the need to establish the levels of disease burden and treatment needs for proper planning of dental services. Well assessed dental treatment needs go a long way in the estimation of resources, rational fund allocation and efficient utilization of dental materials. Dental treatment needs should be 
assessed objectively and subjectively based not only on normative assessment but also on perceived needs and impact so as to obtain the best outcomes. The incorporation of both the clinician's objective assessment and the client's felt needs is essential in ensuring that they participate in the general management of their condition. In common practice today Bradshaw (1978) in a study on the problems and progress in medical care said that the treatment needs of most dental conditions are based on the clinician's judgement using the recommended dental indices1. The age between 13-17 years forms the transition period between childhood and adulthood. The growth changes seen during this stage of life warrants a clear understanding of the health needs in general and support for optimal psychosocial and emotional development. Welbury pointed out that children affected by fluorosis suffer from low self - esteem, social stigma and poor performance in school.

Facial image is an important aspect with regard to an individual's presentation and self-esteem in communication. This is greatly affected by the presence of dental fluorosis among other things like mal-aligned teeth, missing anterior teeth or even congenital malformations of the oral cavity. Globally there is often a permanent stigma associated with dental fluorosis among children or adults. A study conducted in Brazil by Rodriques showed esthetic changes in the permanent dentition are the greatest concern in dental fluorosis. Studies by Welbury and Glasser have observed that if left untreated, dental fluorosis causes embarrassment, psychosocial distress, difficulties in societal adjustment, damage to self-esteem and poor performance for the school-going children. Another study in Kenya by Mwaniki showed that between $60.4 \%$ and $84.3 \%$ of the respondents viewed dental fluorosis as a problem because of its unfavourable effects on an individual's personality. It is important to note that dental fluorosis leads to shyness in expression thereby masking the true personality of an individual. It is further evidenced by a South African study by Mothusi that showed the trauma suffered by young people with dental fluorosis to be depressing such that they requested to have the teeth extracted and replaced with dentures.

Generally, the quality of life is greatly affected by oral diseases, dental fluorosis not being an exception, with a significant impact on the 13-17- year- olds due to their delicate stage of growth and development. Children experience appreciable impacts on oral health related quality of life with the greatest burden being associated with dental caries and to a lesser extent, fluorosis according to a study in Uganda by Robinson. The aspects considered when determining the quality of life with regard to oral diseases using the oral impact of daily performance (OIDP index) include eating, speaking and pronouncing clearly, cleaning teeth, sleeping and relaxing, smiling without embarrassment, maintaining emotional state and enjoying contact with others. A study in Tanzania by Roman on the impact and treatment needs of dental fluorosis where a total of 269 students with dental fluorosis aged
15-18 years (mean age 17.3) were involved, showed that a majority (65.4)\% had severe dental fluorosis (TFI 6-9) while 29.4\% had TFI 4-5 and 5.2\% had TFI 1-3. Most of the students in this study (92.6\%) perceived at least one (OIDP) with the most affected being smiling at $88.1 \%$, emotional stability $81.4 \%$, and having contact with others $75.5 \%$. Studies by Locker and Leake indicated that the oral health status of at risk children and adolescents appeared to have been poor resulting in the need for several treatments including urgent, restorative, periodontal and preventive care Table 1.

Table 1: Distribution of study participants according to age and gender.

\begin{tabular}{|c|c|c|c|}
\hline Age (Years) & $\begin{array}{c}\text { Male (\%) } \\
\mathbf{N = 9 8}\end{array}$ & $\begin{array}{c}\text { Female (\%) } \\
\mathbf{N = 1 5 0}\end{array}$ & $\begin{array}{c}\text { Total (\%) } \\
\mathbf{N = 2 4 8}\end{array}$ \\
\hline 13 & $20(21)$ & $52(35)$ & $72(30)$ \\
\hline 14 & $14(14)$ & $26(17)$ & $40(16)$ \\
\hline 15 & $22(22)$ & $24(16)$ & $46(19)$ \\
\hline 16 & $22(22)$ & $28(19)$ & $50(20)$ \\
\hline 17 & $20(21)$ & $20(13)$ & $40(15)$ \\
\hline \multicolumn{3}{|c|}{ Pearson chi test 2(4) $=7.6792 ; \mathrm{p}=0.104(\mathrm{p} \leq 0.05)$} \\
\hline
\end{tabular}

\section{Materials and Methods}

\section{Study Population}

The study population comprised of 13 -17- years who were born and brought up in Kajiado North District in the first 7 years of life. The target population involved 34,122 children aged 1317 years according to the Kenyan population and housing census 2009 for Kajiado North District. The public primary and secondary school enrolment was approximately 19,065 for the ages 13-17 years in the year 2011 in the study involved 248 children, 98(40\%) males and $150(60 \%)$ females aged between $13-17$ years (mean age $=14.75 \pm 1.45$ ) selected by simple random sampling from 9 schools in Kajiado North District which was purposively selected. They were all clinically examined under natural light for plaque and gingival scores, dental caries, gingivitis, periodontal disease and fluorosis using indices:- Silness and Loe 1963, Loe and Silness 1964, DMFT,CPITN and TFI. Information on biodata, consumption of sugary snacks, brushing was collected using an interviewer administered questionnaire. Water samples were collected for testing for fluoride levels at the government chemist laboratories.

\section{Data analysis}

The clinical examination forms were pre-coded. The quality of data was ensured during the entire study process especially at the data collection point to include completeness of questionnaires, and validity of responses. Data was de - indentified and stored in a password protected data base with access being granted to the statistician. Quality control through data cleaning and validation was censured by counter checking frequencies in the computer and 
any missing data was re - entered. The findings from the study were organized in the form of frequency tables and figures. Computations to calculate disease burden (caries experience, prevalence of gingivitis and periodontitis, treatment needs and the cost of treatment) were done. The independent variable for this analysis was presence/absence of fluorosis while the dependent variables were age, gender, gingivitis, periodontitis, caries experience and cost of treatment. The confounding factors were snacking and oral hygiene practices. For categorical variables association between dependent variables and fluorosis was tested using a Pearson Chi-square test while a student t-test was used for continuous variables and the conventional $P$ value of cut-off of $<0.05$ was used to establish a significant association. To calculate the total DMFT, the total number of teeth per child with caries, filled due to caries, missing due to caries was summed up. For the mean gingival and plaque scores, the total score per child was calculated by summing the individual tooth scores, divided by 6 and the total for the index teeth added and divided by 6 . To determine the agreement rates between assessors, a Cohen kappa score (agreement rate) was calculated for each assessment (tooth and surface) for all children assessed. A median agreement rate was then computed from all individual scores calculated. Data collected was analyzed using statistical package for social sciences (SPSS version 17.0) Table 2.

Table 2: Sources of drinking water.

\begin{tabular}{|c|c|c|}
\hline Water source & Fluorosis (\%) & No fluorosis (\%) \\
\hline Borehole & $57(46)$ & $55(45)$ \\
\hline Tap water & $60(49)$ & $61(49)$ \\
\hline Dam & $4(3)$ & $3(2)$ \\
\hline River & $3(2)$ & $5(4)$ \\
\hline \multicolumn{2}{|c|}{ Pearson Chi test 2(4) $=5.5067 ; \mathrm{p}=0.239(\mathrm{p} \leq 0.05)$} \\
\hline
\end{tabular}

\section{Results}

\section{Socio demographic characteristics}

This study involved 248 children aged between 13-17 years with a mean age of 14.75 years $( \pm 1.45 \mathrm{SD})$ who were all matched for age and gender. The ratio of children with dental fluorosis and those without was 1:1 and the male to female ratio was $2: 3$ and was not statistically significant $[\mathrm{p}=0.104(\mathrm{p} \leq 0.05)]$ as shown in Table 1. There were 241 (97\%) participants born and raised in Kajiado North while $7(3 \%)$ moved to the district before 7 years of age.

\section{Source of water and analysis}

There was a similar pattern on the water sources which was not statistically significant $[p=0.239(p \leq 0.05)]$ for children with fluorosis and those without fluorosis. Most of the study participants consumed borehole water and most of tap water was also from boreholes. Dams and river sources were for a minority group as shown in Table 3.
Table 3: Water analysis findings.

\begin{tabular}{|c|c|c|c|}
\hline S/No & $\begin{array}{c}\text { Name of water } \\
\text { source }\end{array}$ & $\begin{array}{l}\text { Depth in } \\
\text { meters }\end{array}$ & $\begin{array}{l}\text { Fluoride level } \\
(\mathrm{Mg} / \mathrm{l})\end{array}$ \\
\hline 1 & $\begin{array}{c}\text { Gishagi } \\
\text { community } \\
\text { water project }\end{array}$ & 200 & 0.1 \\
\hline 2 & $\begin{array}{l}\text { Embulbul } \\
\text { roadside water } \\
\text { supply }\end{array}$ & 140 & 15.0 \\
\hline 3 & $\begin{array}{c}\text { Embulbul } \\
\text { community } \\
\text { water supply }\end{array}$ & 220 & 8.3 \\
\hline 4 & $\begin{array}{c}\text { Kerarapon } \\
\text { springs }\end{array}$ & unknown & 0.44 \\
\hline 5 & $\begin{array}{l}\text { Ngong main } \\
\text { borehole }\end{array}$ & 190 & 1.0 \\
\hline 6 & Scheme 305 & 180 & 2.0 \\
\hline 7 & $\begin{array}{l}\text { Merisho oloika } \\
\text { water project }\end{array}$ & 196 & 2.5 \\
\hline 8 & $\begin{array}{l}\text { Oloosurutia } \\
\text { borehole }\end{array}$ & 225 & 2.66 \\
\hline 9 & $\begin{array}{l}\text { Kiserian } \\
\text { borehole }\end{array}$ & 150 & 2.0 \\
\hline 10 & $\begin{array}{l}\text { Lemelepo } \\
\text { borehole }\end{array}$ & unknown & 0.5 \\
\hline 11 & $\begin{array}{l}\text { Magadi road } \\
\text { borehole }\end{array}$ & 80 & 1.6 \\
\hline
\end{tabular}

Gishagi borehole which is in a raised ground recorded low fluoride levels of $0.1 \mathrm{ppm}$ as well as Kerarapon springs 0.44 and Lemelepo borehole 0.5 , Ngong main borehole had the recommended levels by WHO of 1ppm. Embulbul roadside and Embulbul community water supplies had very high levels of fluoride at 8.3 and 15ppm (Table 4).

Table 4: Treatment needs for Gingivitis.

\begin{tabular}{|c|c|c|c|}
\hline $\begin{array}{c}\text { Severity of } \\
\text { gingivitis }\end{array}$ & $\begin{array}{c}\text { Treatment } \\
\text { needs }\end{array}$ & Fluorosis (\%) & $\begin{array}{c}\text { No fluorosis } \\
\text { (\%) }\end{array}$ \\
\hline Mild (0.1-1) & OHI & $109(88)$ & $107(86)$ \\
\hline $\begin{array}{c}\text { Moderate } \\
(1.1-2)\end{array}$ & $\begin{array}{c}\text { OHI \& Oral } \\
\text { prophylaxis }\end{array}$ & $12(10)$ & $15(12)$ \\
\hline Severe (2.1-3) & OHI \& Scaling & $3(2)$ & $2(2)$ \\
\hline
\end{tabular}

\section{Tooth brushing habits}

Majority of the children 122(98\%) from each group brushed their teeth, the frequency of brushing was similar where by $113(93 \%)$ with fluorosis and 105(88\%) without used a toothbrush while a chewing stick was used by a few (Table 5). The type of tooth brushing aid used was not statistically significant $\mathrm{p}=0.120(\mathrm{p} \leq 0.05)$. Majority brushed once a day either in the morning after breakfast $61(50 \%)$ and $59(48 \%)$ or in the evening after meals $49(40 \%)$ and $51(42 \%$ for the children with fluorosis and those without fluorosis respectively. Only a small percentage brushed their teeth twice a day. There was no statistical significant difference on the timing of brushing between the groups $[\mathrm{p}=0.180(\mathrm{p} \leq 0.05]$. 
Table 5: Dental Caries treatment needs.

\begin{tabular}{|c|c|c|c|}
\hline S/No & $\begin{array}{c}\text { Treatment } \\
\text { needs }\end{array}$ & $\begin{array}{c}\text { Fluorosis } \\
\mathbf{N = 7 0 ( \% )}\end{array}$ & $\begin{array}{c}\text { No fluorosis } \\
\mathbf{N = 4 6}(\%)\end{array}$ \\
\hline 1 & $\begin{array}{c}\text { Extraction and } \\
\text { partial denture } \\
\text { fabrication }\end{array}$ & $9(12.9)$ & $2(4.3)$ \\
\hline 2 & $\begin{array}{c}\text { One surface } \\
\text { restoration }\end{array}$ & $35(50)$ & $35(76)$ \\
\hline 3 & $\begin{array}{c}\text { Two surface } \\
\text { restoration }\end{array}$ & $17(24.2)$ & $7(15.2)$ \\
\hline 4 & $\begin{array}{c}\text { Three surface } \\
\text { restoration/ } \\
\text { crowns }\end{array}$ & $5(7.1)$ & $2(4.3)$ \\
\hline 5 & $\begin{array}{c}\text { Three surface } \\
\text { composite } \\
\text { restoration }\end{array}$ & $4(5.7)$ & $0(0)$ \\
\hline \multicolumn{2}{|c|}{0.050} \\
\hline
\end{tabular}

Relationship between brushing habits and plaque scores

Generally, children who brushed once after breakfast in both groups had PSs which were statistically significant $\mathrm{p}=0.003(\mathrm{p} \leq 0.05)$ and the children with fluorosis had the lowest PSs of $0.85(0.5)$. The other brushing timings were not statistically significant $\mathrm{p}=1.02(\mathrm{p} \leq 0.05)$ for at night and $\mathrm{p}=0.664(\mathrm{p} \leq 0.05)$ for twice a day as depicted in.

\section{Gingivitis}

Both groups had a similar pattern of treatment needs. There were $109(88 \%)$ for OHI, $12(10 \%)$ OHI and oral prophylaxis, $3(2 \%)$ $\mathrm{OHI}$ and scaling for children with fluorosis. Those without fluorosis, 107(86\%) OHI, 15(12\%) OHI and oral prophylaxis, 2(2\%) OHI and scaling.

\section{Periodontitis}

Of the $3(2.4 \%)$ children with fluorosis who had periodontitis they all required scaling and root planing.

\section{Dental caries}

In both groups, dental restorations in form of one surface fillings were mostly indicated as 35(50\%)/ 35(76\%) for the children with fluorosis/those without. Two surface restorations 5(7.1\%) for fluorosis and $7(15 \%)$ those without fluorosis. Extraction and partial dentures $9(12 \%)$ for fluorosis and $2(4.3 \%)$ those without fluorosis. Three surface composite restorations among children with fluorosis were $4(5.7 \%)$.

\section{Caries experience in relation to consumption of sugary snacks}

In the group with fluorosis the children who consumed sugary snacks twice had a higher DMFT of 0.71(1.4) while children without dental fluorosis and consumed four times scored highest DMFT of $0.83(0.9)$. On the weekly snack consumption, those who sacked once had no caries in both groups $p=0 ; 000(p \leq 0.05)$ which was statistically significant while the highest DMFT was recorded in those who snacked twice/four times for the fluorosis group at $0.64 / 0.6$ while in the group without fluorosis the scores ranged between 0.17-0.25 despite different weekly snacking times.

None of the children who brushed twice had dental caries experience in the fluorosis group for once a day (after breakfast or at night) had a DMFT of 0.5(1)/ 0.73(1.6). For the group without fluorosis, there was some caries experience despite the timings for brushing. Generally there was no statistical significant difference on the brushing timing for both groups. The children who brushed after breakfast had a $\mathrm{p}=0.850(\mathrm{p} \leq 0.05)$, at night only $\mathrm{p}=0.073(\mathrm{p} \leq 0.05)$ and twice a day $p=0.217(p \leq 0.05)$ therefore, brushing did not have any influence on the caries experience.

\section{Cumulative TFI frequencies}

In both jaws TFI 4-5 was the most frequent at 2301(52.3\%) on the labial and lingual surfaces of the anterior teeth in both the maxilla and of the mandibular anterior teeth 2240(51.8\%). There were $321(60.8 \%)$ surfaces which required bleaching and/or micro abrasion or composite masking while 207(39.2\%) surfaces required porcelain veneers or crowns Table 6 .

Table 6: Cumulative TFI scores.

\begin{tabular}{|c|c|c|}
\hline TFI Scores & $\begin{array}{c}\text { Maxillary } \\
\mathbf{N = 4 3 1 8}(\mathbf{4})\end{array}$ & $\begin{array}{c}\text { Mandibular } \\
\mathbf{N = 4 3 2 5}(\mathbf{4})\end{array}$ \\
\hline $0-3$ & $809(18.7)$ & $1055(24.4)$ \\
\hline $4-5$ & $2301(52.3)$ & $2240(51.8)$ \\
\hline $6-9$ & $1208(28)$ & $1030(23.8)$ \\
\hline Chi square p value & \multicolumn{2}{|c|}{0.001} \\
\hline
\end{tabular}

\section{Discussion}

The current study did not find much difference in the treatment needs for gingivitis between the two groups as majority $88 \%$ with fluorosis and $86 \%$ without fluorosis required oral hygiene instructions and oral prophylaxis and in periodontitis the $1.2 \%$ affected required scaling and root planing. Most of the subjects with dental caries required some form of restorations either one, two or three surface amalgam/ composite restorations. A smaller number required extractions and partial dentures. Since radiographs were not taken for this study, it was difficult to ascertain the teeth which were indicated for pulp therapy. Studies done in Trinidad and Tobago by Naidu and Uganda by Nalweyiso clearly indicated that the treatment burden of dental caries is mainly centered on fillings, fissure sealants, pulp therapy and extractions. This study considered treatment needs for dental fluorosis in terms of labial surfaces from canine to canine in the maxillary teeth only. It was established that $48 \%$ of the teeth surfaces required bleaching / micro abrasion, composite masking and 52\% for direct/indirect composite veneers/crowns. In Kenya Mwaniki found that 60.4 - $84.3 \%$ of the respondents viewed dental fluorosis as a problem although the study design was different from the current study. 


\section{Conclusion}

Children with dental fluorosis were burdened more by dental disease and had more treatment needs (dental caries, fluorosis, periodontal disease and gingivitis) when compared to those without dental fluorosis.

\section{(C) \\ This work is licensed under Creative Commons Attribution 4.0 License}

To Submit Your Article Click Here: Submit Article

DOI: 10.32474/MADOHC.2018.02.000133

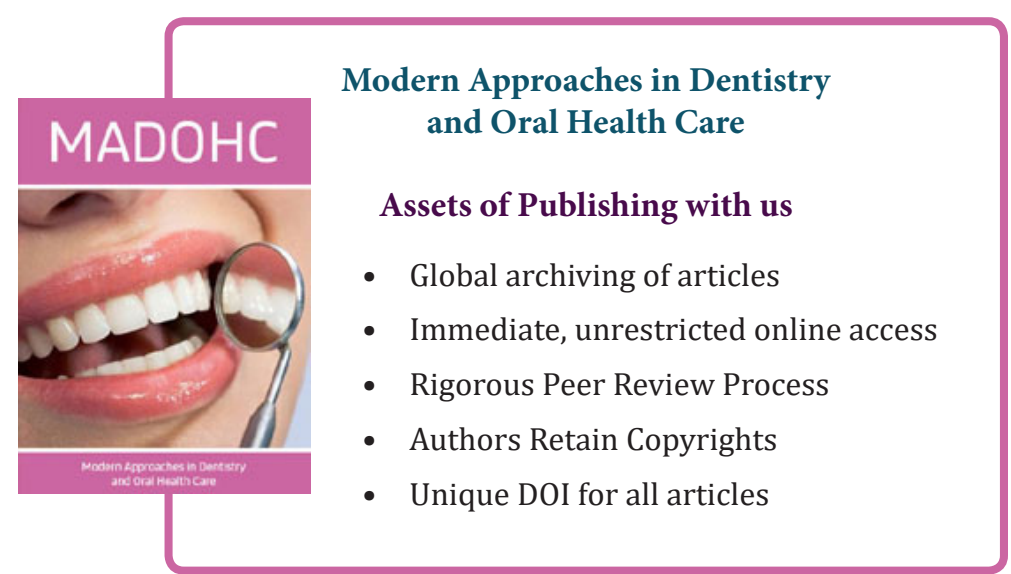

